American Journal of Economics and Business Administration 1 (3): 213-218, 2009

ISSN 1945-5488

(C) 2009 Science Publications

\title{
Emissions Trading is free Market Environmentalism the Answer?
}

\author{
Arpitha Upendra \\ Faculty of Law, Pune University, India
}

\begin{abstract}
Problem statement: Emissions trading are a product of the ideology of free market environmentalism which propagates the utilization of the market and its forces in order to ensure the protection of the environment from industries and other sources of pollution. Approach: Does the market act as an effective tool to resolve the issue of climate change was the primary reason for initiating research in this area. Another issue with the use of market forces is whether the ultimate objective of environmental protection is achieved in this study this issue is given detailed consideration by aligning emissions trading with the well established principles and environmental ethics. Results: In this study I will critically examine this mechanism and analyze whether it synchronizes with the existing and accepted forms of environment jurisprudential principles and ethics, the 'polluter-pays' principle in particular. grandfathering has been the primary reason why economists and environmental lawyers across the world argue that it goes against the 'polluter-pays' principle, in this study I will put forth a comparison between grandfathering and auctioning as a means to provide the carbon emission allowances. Conclusion: In conclusion, this study will come to a more nuanced proposition, wherein I suggest an alternate mechanism for trading of emissions which is more in tune with the international environment jurisprudence and ethics. In this study I arrive at a nuanced conclusion where the current mechanism has been altered to suit the principles established. This is achieved by auctioning where the polluter pays for the right to pollute and the funds obtained from this mechanism will be deposited in an environmental obligation and burden fund which will be utilized in the achievement of environmental protection. The primary significance of this research work is that it brings the current mechanism established in consonance with sound environmental principles and ethics. Through this it makes this mechanism address the environmental paradigm which is presently being ignored.
\end{abstract}

Key words: Emission trading and polluter pays principle

\section{INTRODUCTION}

Emissions trading have found its place as a leading means to combat the problem of pollution; emission trading owes its origin to free market environmentalism which is founded on two basic principles which they attribute to be the primary reasons for the rise in environmental problems:

- That the laws governing property rights fail to either adequately protect or define those rights

- Laws governing class or individual tort claims that provide polluters with immunity from tort claims, or interfere with those claims in such a way as to make it difficult to legally sustain them ${ }^{[1]}$

Free market environmentalism places focus on the concept that with the presence of clearly defined property rights comes ownership and from it responsibility to utilize these acquired resources (carbon dioxide) in a more optimized and prudent manner, this however does not seem to be functioning as expected, currently emissions trading has only allowed the increase in emission levels by means of purchase of more credits or allowances by industries, this however does not render this mechanism useless but one which can be further modified to comply with environmental ethics and principles to become a more eco centric system of trading.

The emissions trading system currently in place: The current emissions trading mechanism works on what is known as a cap-and-trade system wherein there is an overall limitation for the emission of carbon and green house gases for each nation, at a domestic level each polluting industry will be allocated a specific amount of allowances free of cost based on historical emissions, if that industry emits below the level of permits granted the excess permits may be traded with other industry's who pollute more than the allowances granted to them, here is where the polluter pays as he has to purchase those excess credits required. This similar concept is 
also practiced at a global level except in this case the trading takes place between nations and not polluting industries. The first application of emissions trading was seen in USA under the Clean Air Act, 1990 which established a system for the trading of Sulphur dioxide this proved to be a successful means of achieving the objective of reducing their emissions but did nothing to compensate for the environmental damage being done.

The Kyoto protocol in article 17 proposes emissions trading as a means for Annex I countries to meet their obligation under article 3 of the protocol (text of the Kyoto protocol to the UNFCCC). The flaw that lies in the protocol is that it fails to specify the exact procedure to be followed and allows the countries themselves to decide the principles which govern the trading system; although this establishes flexibility it also gives room to the possibility of principles or guidelines being unequal and against the sound concepts of environmental jurisprudence. The protocol also fails to bring in the fact of historical obligation as developed countries are responsible for most of the carbon present in the atmosphere as opposed to developing countries; the current system does not take this aspect into account. Apart from the fact of historical obligation, the protocol does not seek to regulate the process of development in developing nations keeping in mind that these countries are going to be the primary polluters as they undertake carbon intensive processes in the future. Emissions trading as a system would have to change in order to accommodate these various issues so that it can have the desired effect of protecting the environment against pollution.

The polluter-pays principle: The principle also known as Extended Polluter Responsibility (EPR) was first described by the Swedish government in 1975. This concept basically speaks of shifting of responsibility to deal with the damaging effects of pollution from the government i.e. from the taxpayers to the polluters as they are the root cause for such damage in whatever form. This concept gained momentum when it was advocated by the Organization for Economic CoOperation and Development (OECD) along with the European Community (EC) countries.

The OECD defines EPR as follows: a concept where manufacturers and importers of products should bear a significant degree of responsibility for the environmental impacts of their products throughout the product life-cycle, including upstream impacts inherent in the selection of materials for the products, impacts from manufacturers' production process itself and downstream impacts from the use and disposal of the products. Producers accept their responsibility when designing their products to minimize life-cycle environmental impacts and when accepting legal, physical or socio-economic responsibility for environmental impacts that cannot be eliminated by $\operatorname{design}{ }^{[2]}$.

This principle has also found its way into the realm of international environmental law as it is enumerated in the Rio declaration as principle 16 which reads as follows:

Principle 16: National authorities should endeavor to promote the internalization of environmental costs and the use of economic instruments, taking into account the approach that the polluter should, in principle, bear the cost of pollution, with due regard to the public interest and without distorting international trade and investment $^{[3]}$.

This principle can be broken down into its various facets to include the following:

- The polluter has to pay for the environmental damage done through his pollution

- There will be a shift in the burden to bear the cost of environmental harm from the government to the polluter

- It advocates internalization of environmental costs thus increasing the economic burden on the polluter and acting as a deterrent to pollute

- Under this principle the polluter is to also bear the cost of pollution prevention and control measures

Some of the practical applications of this principle can be seen in the Convention on the Protection and the Use of Transboundary Watercourses and International Lakes, the 1992 Helsinki Convention on the Protection of the Marine Environment of the Baltic Sea Area and the 1996 Protocol to the London Dumping Convention, to name just a few, endorses this principle in various ways $^{[4]}$. Interpretation of this principle can be best understood as put by Verhoef who states as follows:

"(...) the question of whether the polluter should pay (...) may often lead to different outcomes in terms of both allocative efficiency and equity. (...) This ambiguity in the interpretation of the polluter pays principle is, unfortunately, often overlooked"

This brings us to two possible interpretations to the above principle.

The efficiency interpretation:

The equity interpretation: The efficiency interpretation highlights that through internalization of 
costs it will lead to efficient allocation of resources and does not ponder over the issue of distribution of costs whereas the Equity interpretation acknowledges a wide range of issues the primary one being equity in the distribution of costs for bearing environmental damage and burden.

For the purpose of this study both the interpretations have been given due consideration and are considered to important to present a well encompassed view of this principle.

Emissions trading and the polluter pays principle: Dworkin described the nature of a principle in his analogy of a Principle to a Doughnut ${ }^{[5]}$ wherein he states that although principles have no enforceable value they act as a boundary within which all legislation and statutes should fall. Keeping this in mind we will now examine whether Emissions trading complies with the polluter pays principle in Fig. 1.

At present Emissions trading is accepted to be one of the means by which this principle is practiced however it does not happen in the true sense, if one observes here the polluter pays but in order to pollute more and provides no compensation for the environmental damage done. The variant of this principle which speaks of the polluters responsibility to compensate for the damage has been completely ignored it only incorporates the deterrent factor of the principle. Under the current mechanism there is only one situation in which the polluter has been made to pay when he exceeds the level of allowances granted thus if he exercises his so called ' right to pollute' within the level of emissions he is not been made to pay, despite the fact that he still pollutes.

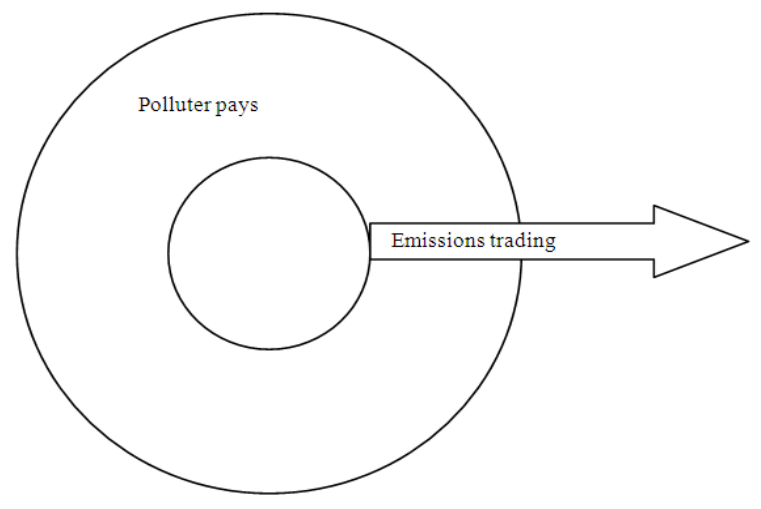

Fig. 1: Diagramatic representation of Dworkin's analogy
Reasons for which the current emissions trading system is inconsistent with the polluter pays principle:

- It does not make provision for the polluter to pay for the environmental damage done by his polluting activities

- It grants the right to pollute with no corresponding burden up to a certain extent which goes against the core of this principle

- Grandfathering which means that initially the countries give away emission credits or allowances free of cost to the various industries or nations as the case may be thus they are being given the right to pollute without having to pay

The basis of the polluter pays principle as previously explained is that the polluter pays for both environmental damage done and preventive measures ${ }^{[4]}$, the new facet which I seek to introduce is that the polluter should even pay for procuring the right to pollute, without whose acquisition he cannot pollute anything, in the case of emissions trading it brings in the aspect of auctioning where the polluters will have to purchase the allowances as opposed to being given the permits free of cost.

Advantages of introducing the concept of the polluter paying for the rights to pollute:

- It will act as a stronger deterrent to pollute and will usher a sense of consciousness

- With the economic burden increasing with the increase in Pollution countries as well as industries will be given a stronger incentive to invest in ecologically sound technologies and methods; it will also act as an impetus to engage in more research in this regard. Thus it will be a more long term solution as opposed to a temporary system of managing pollution

- As it proves to be more expensive to pollute countries and industries will start to utilize these resources to the maximum and more efficiently which will enable in constituting a stable economy as well as aid in the application of the doctrine of sustainable development

Practical application of the polluter pays for the right to pollute ideology: This concept of making the polluter pay for the right to pollute is not an impractical one although its origin comes from an idealistic background. it finds its place in the system of 
auctioning credits, with auctioning the polluter is made to purchase the allowances prior to engaging in his polluting activity thus he purchases a sanction to pollute with this the polluter will be more weary and will purchase more or less the amount required. It will also motivate the polluter to reduce investment in the purchase of credits by increasing investment in more ecologically friendly technologies which will in turn increase his profits in the long run. In today's industrialized and commercial environment its only motivation in the form of profit that has more bearing and this seeks to comply by that norm if established. The question as to the very establishment of this system will be one that is bound to arise; the primary reason for nations to adopt this system will be to comply with the doctrine of sustainable development, more efficient utilization of natural resources and increase in natural resource security for future generations as well as a cleaner environment with its own benefits.

The body of international environmental law will have to make provision for the establishment of an impartial and strong committee from whom these sanctions can be purchased. This requires a scientific and detailed analysis into the mechanism of auctioning in order to define the powers and functions of this committee. It will be the duty of this committee to ensure that the granting of sanctions is need based and in strict compliance with the principles put forth in Agenda 21. Special standards of right to pollute should be created for the developed and developing countries such that the trust deficit between the nations is reduced. I will further explore the functioning and composition of this committee in the later part of the study where I suggest a new mechanism for emissions trading.

Grandfathering and auctioning: As previously explained the primary difference between grandfathering and auctioning of emission rights is that in the case of grandfathering the emission rights and allowances are given away free of cost whereas in the case of auctioning the polluter has to purchase the emission rights and allowances ${ }^{[6]}$. Auctioning of these emission rights is more in tune with the polluter pays principle and environmental ethics thus forming a stronger base for a trading system.

Reasons why auctioning is more in compliance with the polluter pays principle and environmental ethics:

- Here the polluter pays initially itself for the carbon emissions this ensures full compliance with the concept of internalization of environmental costs
- It explicitly allows a smooth shifting of the burden from the taxpayer to the polluter even before polluting thus a more efficient application of this principle

- It is a more eco centric manner to deal with emission credits as even before damage has been sustained by the environment compensation has already been provided for.

- It gives policy makers a source of funding to prepare the environment for the damage that it will sustain and aid in reducing its effects as opposed to taking measures after the damage has been done

- It indirectly also makes the polluter to pay for prevention and control measures as he begins to invest in more alternative and environmentally sound technologies thus the ultimate benefactor being the environment makes this concept ethically strong

This will be one of the main aspects that will be suggested for the new mechanism and will be incorporated with specific guidelines and limitations.

Emissions trading and environmental ethics: Environmental ethics refers to the ethical aspect of environmental law. Social movements and activism have aided in shaping this area of environmental law. Green movements across the world have adopted different schools of thought even taking a violent form like eco-terrorism. This area links social practices with environmental problems which are a link that needs to be understood to better implement and formulate environmental policies. Environmental problems change and even take new forms with change in social practices. In India one can clearly see the impact on the environment with change in social practices for instance the use of more cloth bags in order to avoid plastic which is harmful thus there is modification in social mannerisms to suit their environment. In environmental ethics there are two schools of thought:

- Anthropocentric: Where the law and change in social mannerisms brought by the law use the 'benefit for mankind' as the primary motivation to conserve the environment. In such a system it recognizes the rights of man but fails to acknowledge the rights of other species

- Earth or Biocentricism: In such a school of thought man is considered to be an integral part of the web of life and a law based on this ideology will result in due rights being given to other species and the earth at large. Here the law will motivate social 
change through using the benefit of the environment as a whole ${ }^{[7]}$

If the biocentric approach is adopted the mechanism of emissions trading would not be the same. It is currently not taken into consideration, the question that might arise is what is the advantage of adopting a school of thought that more or less leads to a complicated solution with the problem of multiplicity of rights, in this study I will not be applying this ideology as a whole but only one of its facets which is that the environment should be the main priority. That is man should have to change his mannerisms to suit the comfort of the environment and not the other way round. The change should be brought about by man to adapt with the problem of pollution and not one where the change is being made yet in such a manner that mans rights to pollute are given more emphasis and lee way, if this system is adopted it will only lead to a healthier future in both economic and social terms. Keeping the above ideology in mind I will now proceed to describe in great detail the changes to be made to the emissions trading system.

Modified emissions trading system: This system has been modified to be consonance with the polluter pays principle and environmental ethics.

Emissions trading authority: The emissions trading authority would be the apex body from whom the carbon credits or allowances can be purchased by every nation. It will be the function of this body to decide the carbon capping for each country taking into consideration the following:

- The variation in capping between the developed and developing countries with due consideration being given to the fact of historical obligation

- The fact that developing countries will be undertaking carbon intensive processes in the future

- Historical emission levels

Once the carbon caps have been placed the respective countries will have to purchase each of these permits prior to polluting and the money generated from this sale will be directly transferred to a fund called the Environmental obligation and burden fund (EOBF). The control of this fund will be with the emissions trading authority. In this manner it will ensure that the polluter also pays for the environmental damage.
In case a nation purchases excess credits required a corresponding environmental obligation fee would have to be paid to compensate for the future damage going to be done. It will be the duty of the authority to ensure that the fees has been duly paid and collected. The value of this fee will be determined in terms of dollars and each currency to the corresponding value will have to be paid. This fee is subject to change depending upon the environmental damage foreseen. The problem which arises here is how to value the environmental damage. This damage is going to be valued in terms of funds required to engage in activities to reduce the effects of global warming like afforestation, alternate sources of energy, research in this regard etc. it will be the power of the authority to determine the allocation to the various activities. The distribution to nations will function on the principle of need depending on the environmental harm being suffered.

Environmental Obligation and Burden Fund (EOBF): This fund that I propose to establish in order provide a resource for countries to be able to undertake activities to improve the situation of climate change.

\section{Sources:}

- Money received from the purchase of carbon allowances

- Environmental obligation fees collected from nations who purchase emission credits

Uses: It will be used for activities that can aid the environment combating the issue of global warming some of the examples are as follows:

- Afforestation

- Alternate sources of energy

- Research in renewable sources of energy

- Ecologically friendly technology

- Funding for research in this area of technology

The presence of these resources will play a key in bringing about changes in all industrialized processes and will only aid in adapting.

Allocation: The allocation to various nations should be made need based and through which countries with higher degree of need can be given top priority.

Thus through the above mentioned changes the polluter is paying for:

- Environmental damage

- Prevention and control of emissions

- The very right to pollute 


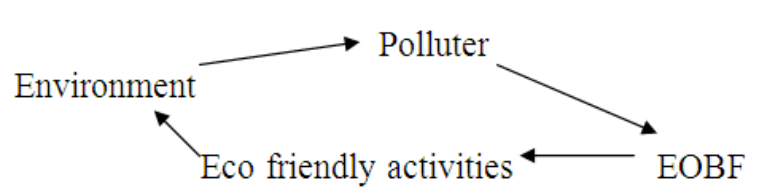

Fig. 2: Cycle of flow of funds in the new emission trading mechanism

This explicitly ensures perfect compliance with the polluter pays principle. Also as the money obtained is being used only for the environment and its benefit it is ethically sound and biocentric in its approach. Figure 2 clearly shows the cycle of this mechanism and its benefits.

In the Fig. 2 it shows how the polluter pays for the right to pollute which is then deposited into the EOBF which is in turn utilized for environment friendly activities which benefit the environment and ultimately the polluter as a cleaner environment has positive economic and social implications.

This mechanism does not do away with the emissions trading system all together but only includes one primary change which is auctioning and the funds generated from this ensure that the polluter pays for environmental damage. This mechanism provides identification to the various facets of this principle that was ignored before thus rendering it sounder and more advantageous to the environment. This mechanism can better equip us to meet the environmental problems of the future through prevention measures that will be undertaken by the emissions trading authority.

\section{CONCLUSION}

In conclusion in this study I come to a nuanced view that free market environmentalism has the potential to solve the climate crisis but only if it abides by the set principles of environmental law laid down and ethics specified. In combination with these principles the system can aid in the problems faced due to climate change. Whether free market environmentalism through emissions trading alone can solve the climate crisis is a farce it requires a more integrated approach of resource conservation, regulation of development especially carbon intensive processes and research in the areas of alternate sources of energy. Thus the mechanism suggested in this study gives a clear view of the flaws in the existing system to combat the issue of climate change and provides a more stable system which will harness resources for the benefit of the environment and mankind will be able to reap the benefits in the long run as it gives a more futuristic approach to the issue as opposed to the finding of a temporary solution.

\section{REFERENCES}

1. Anderson, T.L. and D.R. Leal, 1991. Free-Market Environmentalizm. ISBN: 0-8133-1101-2.

2. Environment Directorate, 1994-2006. Fact sheet: Extended producer responsibility. http://www.oecd.org/document/53/0,3343,en_2649 _34395_37284725_1_1_1_1,00.html

3. Word Press, 1992. Text of the RIO declaration on environment and development. http://win2vin.wordpress.com/2009/08/12/the-riodeclaration-on-environment-and-development1992/

4. Woerdman, E., A. Arcuri and C. Stefano, 2008. Emissions trading and the polluter-pays principle: Do polluters pay under grandfathering? Rev. Law Econ., 4. DOI: 10.2202/1555-5879.1189

5. Dworkin, R., 1997. Freedom's Law: The Moral Reading of the American Constitution. Harvard University Press, ISBN: 10: 0674319281, pp: 416.

6. Bugge, H.C., 1996. The Principles of Polluter Pays in Economics and Law. In: Law and Economics of the Environment, Eide E. and R. van der Bergh (Eds.). Juridisk Forlag, Oslo, ISBN: 8275130344, pp: 251.

7. Barry, T., 1999. The Great Work-Our Way into the Future. 1st Edn., Harmony, ISBN: 10: 0609605259, pp: 256. 